\title{
Efficacy and safety of sedation during endoscopic submucosal dissection of gastric cancers using a comparative trial of propofol versus midazolam
}

\section{OPEN-
ACCESS-}

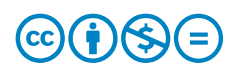

\author{
Authors \\ Hiromasa Ohira² \\ Institutions \\ 1 Department of Endoscopy, Fukushima Medical \\ University Hospital, Fukushima, Japan \\ 2 Department of Gastroenterology, Fukushima Medical \\ University School of Medicine, Fukushima, Japan \\ 3 Department of Advanced Gastrointestinal Endoscopy, \\ Fukushima Medical University, Fukushima, Japan
}

Hitomi Kikuchi ${ }^{1,2}$, Takuto Hikichi ${ }^{1}$, Ko Watanabe ${ }^{1,2}$, Jun Nakamura ${ }^{1,2}$, Tadayuki Takagi ${ }^{2}$, Rei Suzuki ${ }^{2}$, Mitsuru

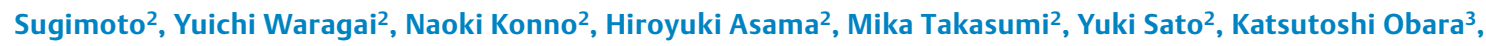

submitted 22.1.2017

accepted after revision 11.9 .2017

\author{
Bibliography \\ DOI https://doi.org/10.1055/s-0043-122225 | \\ Endoscopy International Open 2018; 06: E51-E57 \\ (c) Georg Thieme Verlag KG Stuttgart · New York \\ ISSN 2364-3722
}

Corresponding author

Takuto Hikichi, MD, PhD, Director and Associate Professor, Department of Endoscopy, Fukushima Medical University Hospital, 1 Hikarigaoka, Fukushima, Japan, 960-1295

Fax: +81-24-547-1586

takuto@fmu.ac.jp

\section{ABSTRACT}

Background and study aims Proper sedation is necessary for the safe and satisfactory completion of endoscopic submucosal dissection (ESD) for early gastric cancer. This study was conducted as a comparative trial of efficacy and safety, comparing propofol-based sedation and midazolam-based sedation during ESD of early gastric cancer patients.

Patients and methods This study examined 64 lesions in 58 patients treated using ESD with midazolam plus pentazocine between July 2013 and January 2014 (group M) and 237 lesions in 216 patients treated by ESD using propofol plus pentazocine between February 2014 and December 2015 (group P). The two groups were compared in terms of the frequency of body movement during ESD as the primary outcome and in terms of the procedure time, en bloc resection rate, intraoperative change in cardiorespiratory dynamics, and postoperative awareness as the secondary outcomes. Body movement was defined as movement by a patient that required interruption of the procedure or restraint of the patient's body trunk, and addition of a sedative agent.

Results The median frequency of body movement during ESD was significantly lower in group $P$ (0 times) than in group M (3 times) $(P<0.001)$. No significant difference was found for the mean procedure time $(117 \mathrm{~min}$ in group $\mathrm{P}$; 127 min in group M). Although no significant difference was found in the incidence of hypoxemia, bradycardia, or bradypnea, the incidence of hypotension was significantly higher in group $\mathrm{P}(31.5 \%)$ than in group $M(6.9 \%)(P=$ $0.004)$. Patients in group $P$ had significantly higher postoperative awareness immediately after ESD and at 1 hour after ESD ( $P=0.002$ and 0.022 , respectively).

Conclusion These results demonstrate the efficacy and safety of propofol-based sedation for gastric ESD.

\section{Introduction}

Endoscopic submucosal dissection (ESD) for early gastric cancer, a minimally invasive technique that enables en bloc tumor resection, has become a standard treatment for early gastric cancer in Japan [1,2]. It has allowed endoscopic treatment to be applied to large lesions and lesions with an ulcer scar [3, 4], provided that the lesions are localized in the mucosa. Because
ESD is a technically demanding [5] and lengthy procedure, the need exists for a sedation method that provides a consistent level of sedation during ESD for the safe and satisfactory completion of the procedure [6].

Increasing attention has been given to the use of propofolbased sedation in ESD. Propofol is known to have a narrow therapeutic range and an appreciable effect on cardiorespiratory dynamics [7-9]. Propofol use is also characterized by a rapid 
onset and short duration of action [10], thereby providing stable anesthesia and good postoperative awareness $[6,11]$. Results of some studies have suggested that the use of propofol leads to substantial improvement in patient acceptance of and satisfaction with endoscopic examination [12-17]. Since the introduction of ESD, we have used midazolam-based sedation. Moreover, we have experienced cases in which body movement could not be controlled and the operation had to be discontinued. We have therefore introduced propofol-based sedation into our ESD protocol since February 2014. This study was conducted to compare the efficacy and safety of propofolbased sedation to that of midazolam-based sedation in ESD for early gastric cancer patients.

\section{Patients and methods}

\section{Patients}

This study assessed 64 lesions in 58 patients treated by gastric ESD using midazolam-based sedation between July 2013 and January 2014 (group M) and 237 lesions in 216 patients treated by gastric ESD using propofol-based sedation between February 2014 and December 2015 (group P). All patients underwent chest radiography, electrocardiography, spirometry, and blood analysis, including liver and renal function tests, before the treatment. All patients provided written informed consent before the procedures. This study was conducted with the approval of the Ethics Committee of Fukushima Medical University (approval No. 2058).

\section{Sedation and monitoring protocols}

In group $\mathrm{M}$, anesthesia was induced by a bolus intravenous (IV) infusion of $15 \mathrm{mg}$ pentazocine plus $2.5-5 \mathrm{mg}$ midazolam. In the event of body movement, an additional bolus IV infusion of $2.5 \mathrm{mg}$ midazolam or $7.5 \mathrm{mg}$ pentazocine was given. If the patient did not respond to the additional sedative, then more sedative was administered equally while carefully monitoring cardiorespiratory dynamics. After the completion of ESD, patients recovered from anesthesia with the administration of $0.5 \mathrm{mg}$ flumazenil. In group $\mathrm{P}$, anesthesia was induced using a bolus IV infusion of $15 \mathrm{mg}$ pentazocine plus $20 \mathrm{mg}$ propofol, followed by the continuous infusion of propofol using an infusion pump. The continuous infusion rate was set initially at $10 \mathrm{mg} /$ $\mathrm{kg} / \mathrm{h}$ and was gradually tapered every 1 minute (min) to 5, 4, and $3 \mathrm{mg} / \mathrm{kg} / \mathrm{h}$. The rate was maintained at $3-5 \mathrm{mg} / \mathrm{kg} / \mathrm{h}$ during ESD. In addition, $7.5 \mathrm{mg}$ pentazocine was administered every 30 min during ESD. In the event of body movement, a bolus IV infusion of $20 \mathrm{mg}$ propofol was given. Also, the continuous infusion rate was increased. After the completion of ESD, the continuous propofol infusion was stopped to allow the patient to recover from anesthesia. The depth of sedation was adjusted to "deep sedation" without using the bispectral index monitoring, under which spontaneous breathing is maintained, according to the "Practice guidelines for sedation and analgesia by non-anesthesiologists" published by the American Society of Anesthesiologists (ASA) [18].

During ESD, patients received oxygen via a nasal cannula at a rate of $2 \mathrm{~L} / \mathrm{min}$. The blood pressure (BP) was measured immedi- ately after sedation and then every minute until the insertion of the endoscope and every 5 min thereafter. The heart rate (HR), respiratory rate $(\mathrm{RR})$, and $\mathrm{SpO}_{2}$ were monitored continuously. The RR was measured using an acoustic respiration monitor (Rad-87 ${ }^{\mathrm{TM}}$; Masimo, Tokyo, Japan). In addition to the physician, sedation was managed exclusively by an endoscopist with expertise in anesthesia. The endoscopist evaluated the frequency of body movement and decided to administer bolus midazolam, propofol, or pentazocine. The endoscopist who administered sedation was in the same room at all times during ESD procedures. A nurse checked the vital signs of the patients and recorded the data. The nurse who checked the vital signs recorded the frequency of body movement during ESD, as directed by a previously established protocol. Therefore, although this study is retrospective, we were able to obtain these data. The nurse recording the vital signs had no other duties. She devoted herself to monitoring the patient's condition. Body movement was defined as a patient's movement that required interrupting the procedure or restraining the patient's body trunk and adding the sedative agent. All patients were restrained with simple restraining bands.

\section{ESD procedure}

ESD was performed using a Dual Knife (KD-650L; Olympus Medical Systems Corp., Tokyo, Japan), a Flex Knife (KD-630L; Olympus Medical Systems Corp.), an IT Knife (KD-610L; Olympus Medical Systems Corp.) or an IT Knife 2 (KD-611L; Olympus Medical Systems Corp.). For the submucosal injection solution, a $1: 1$ solution of $0.4 \%$ sodium hyaluronate (MucoUp; Johnson \& Johnson K. K., Tokyo, Japan) and glycerol (Chugai Pharmaceutical Co. Ltd., Tokyo, Japan) was injected into the submucosa using a 25-G injection needle (ImpactFlow; TOP Corp., Tokyo, Japan). A hemostatic forceps (Coagrasper; FD410LR; Olympus Medical Systems Corp.) was used for the prophylactic coagulation of blood vessels and hemostasis for intraoperative bleeding. A VIO300 D or ICC200 (ERBE Elektromedizin GmbH, Tübingen, Germany) was used as the high-frequency generator. All ESDs were performed by expert physicians who were boardcertified gastroenterological endoscopists of the Japan Gastroenterological Endoscopy Society or by less-experienced physicians (i. e., those who had performed fewer than 50 ESD procedures) under the supervision of the expert physicians. An expert endoscopist took over when the procedural time was expected to exceed 2 hours or when complications such as perforation or respiratory depression occurred.

\section{Outcomes}

The primary outcome was the frequency of body movement during ESD. The secondary outcomes were procedure time, en bloc resection rate, cardiorespiratory dynamics during ESD, and postoperative awareness. The procedure time was defined as the time from the insertion of endoscope to the withdrawal of endoscope after the completion of tumor resection. For cardiorespiratory dynamics, systolic blood pressure $(s B P)<90 \mathrm{mmHg}$ was defined as hypotension, $\mathrm{HR}<50$ beats/min as bradycardia, $\mathrm{RR}<8$ breaths/min as bradypnea, and $\mathrm{SpO}_{2}<90 \%$ as hypoxemia. Postoperative awareness was evaluated immediately, 
- Table 1 Patient characteristics.

\begin{tabular}{|c|c|c|c|c|}
\hline & Group M $(n=58)$ & Group P $(n=216)$ & $95 \% \mathrm{Cl}$ & $P$ value \\
\hline Age, mean $\pm S D$, yr. & $74.3 \pm 8.4$ & $72.9 \pm 8.7$ & $-.130-3.925$ & 0.277 \\
\hline \multicolumn{3}{|l|}{ Gender, n (\%) } & $0.480-1.811$ & 0.836 \\
\hline - Male & $43(74.1)$ & $163(75.5)$ & & \\
\hline - Female & $15(25.9)$ & $53(25.5)$ & & \\
\hline Body weight, mean $\pm \mathrm{SD}$, $\mathrm{kg}$ & $58.3 \pm 12.9$ & $59.3 \pm 10.5$ & $-4.238-2.197$ & 0.533 \\
\hline \multicolumn{3}{|l|}{ ASA classification, n (\%) } & $0.592-35.127$ & 0.111 \\
\hline$\cdot 1 / 11$ & $57(98.3)$ & $200(92.6)$ & & \\
\hline . III & $1(1.7)$ & $16(7.4)$ & & \\
\hline \multicolumn{5}{|c|}{ Vital signs before sedation, median (range) } \\
\hline Systolic BP, mmHg & $145(113-186)$ & $139(97-217)$ & & 0.052 \\
\hline $\mathrm{HR}$, beats/min & $69(46-98)$ & $67(46-99)$ & & 0.052 \\
\hline $\mathrm{SpO}_{2}, \%$ & $98(94-100)$ & $98(93-100)$ & & 0.218 \\
\hline RR, breaths/min & $16(9-24)$ & $16(7-30)$ & & 0.229 \\
\hline
\end{tabular}

1 hour, and 3 hours after ESD according to the Observer's Assessment of Awareness/Sedation (OAA/S) scale, and the percentage of patients with an OAA/S score of 5 (awake or responding immediately to quiet name calling) was determined. Doctors of the ESD team, including the physician, checked the recovery time after ESD.

\section{Statistical analyses}

Continuous data were expressed as the mean \pm standard deviation, median, and range. Differences were analyzed for statistical significance using $X^{2}$ test, Student's $t$-test and Mann-Whitney $U$-test; differences were considered significant when the $P$ value was less than $5 \%$. Analyses were performed using Statcel 2 software (OMS Publishing Inc., Tokorozawa, Japan).

\section{Results}

No significant difference was found between the two groups in terms of patient data including age, sex, body weight, ASA score, pretreatment sBP, $\mathrm{HR}, \mathrm{SpO}_{2}$, and RR ( Table 1). One patient in group $\mathrm{P}$ and 16 patients in group $\mathrm{M}$ were assigned an ASA score of III. All of these patients had cardiovascular disease (angina pectoris or old myocardial infarction). However, their disease conditions were stable. Therefore, we confirmed them as suitable candidates to undergo ESD. The ESD procedure outcomes were also similar between the two groups, with no significant difference in terms of histological type, invasion depth, specimen diameter, tumor diameter, procedure time (117 min in group $\mathrm{P} ; 127$ min in group $\mathrm{M}$ ), or en bloc resection rate ( $\triangleright \mathrm{Ta}$ ble 2).

In group $\mathrm{P}$, the median total amount of propofol was $454.5 \mathrm{mg}$. The median total amount of pentazocine was
$37.5 \mathrm{mg}$. In contrast, in group $\mathrm{M}$, the median total amount of midazolam was $15 \mathrm{mg}$. The median total amount of pentazocine was $30 \mathrm{mg}$. During ESD, significantly more bolus injections were made of midazolam (5 times) than of propofol (1 time) $(P<0.001 ;>$ Table 3$)$.

The median frequency of body movement during ESD was significantly lower in group $P$ (0 times) than in group $M$ ( 3 times) $(P<0.001$; $>$ Table 4). One patient in group $M$ had body movement that required interruption of ESD because of difficulty in continuing the procedure; that patient underwent ESD under general anesthesia in an operation room 2 days later. The minimum values of $s B P, H R$, and RR during ESD were significantly lower in group $P$ than in group $M(P<0.001, P<0.001$ and $P=0.005$, respectively; $>$ Table 4). These abnormalities were rapidly reversed by modifying the propofol infusion rate and/or increasing the oxygen flow. Therefore, they did not affect the continuation of the procedure. A significantly higher percentage of patients in group $P$ experienced hypotension during ESD $(P=0.004)$, although no significant difference was found between the two groups in the incidence of bradycardia, hypoxemia, and bradypnea during ESD ( $\downarrow$ Table 4 ). The use of an acoustic respiration monitor for the precise measurement of the respiratory rate also enabled the detection of hypoxemia before any decrease in $\mathrm{SpO}_{2}$ was observed. No patient in any group required any medication to rectify sedation-induced hemodynamic derangement.

Fifty-two patients in group $\mathrm{M}$ and 189 patients in group $\mathrm{P}$ had procedure times longer than one hour. The percentages of patients in group $\mathrm{P}$ who experienced hypotension, bradycardia, and bradypnea during ESD were significantly higher than those in group $\mathrm{M}(P<0.001, P=0.043$, and $P=0.015$, respectively $)$, al- 
- Table 2 Lesion characteristics and procedure outcomes.

\begin{tabular}{|c|c|c|c|c|}
\hline & Group M $(n=64)$ & Group P $(n=237)$ & $95 \% \mathrm{Cl}$ & $P$ value \\
\hline \multicolumn{3}{|l|}{ Tumor location, n (\%) } & $0.364-1.624$ & $0.611^{1}$ \\
\hline - Upper & $10(15.6)$ & $46(19.4)$ & & \\
\hline - Middle & $26(40.6)$ & $99(41.8)$ & & \\
\hline - Lower & $28(43.8)$ & $92(38.8)$ & & \\
\hline Histological type, $\mathrm{n}(\%)^{2}$ & & & $0.176-1.989$ & 0.610 \\
\hline - Differentiated type & $60(93.7)$ & $228(96.2)$ & & \\
\hline - Undifferentiated type & $4(6.3)$ & $9(3.8)$ & & \\
\hline Depth of invasion, $\mathrm{n}(\%)$ & & & $0.317-1.522$ & $0.360^{3}$ \\
\hline - $M$ & $54(84.4)$ & $210(88.6)$ & & \\
\hline - SM1 & $5(7.8)$ & $9(3.8)$ & & \\
\hline - SM2 & $5(7.8)$ & $18(7.6)$ & & \\
\hline Specimen diameter, mean \pm SD, mm & $42.0 \pm 13.2$ & $39.6 \pm 13.2$ & $-1.319-6.145$ & 0.204 \\
\hline Tumor diameter, mean $\pm \mathrm{SD}, \mathrm{mm}$ & $18.3 \pm 13.0$ & $17.8 \pm 13.0$ & $-3.063-4.123$ & 0.772 \\
\hline Procedure time, mean $\pm S D$, min & $127.0 \pm 67.0$ & $117.3 \pm 63.0$ & $-8.968-28.205$ & 0.309 \\
\hline \multicolumn{5}{|c|}{ Procedure time each location, mean $\pm S D$, min } \\
\hline - Upper & $145.8 \pm 52.9$ & $149.6 \pm 81.9$ & $-58.195-50.708$ & 0.891 \\
\hline - Middle & $149.2 \pm 82.3$ & $121.7 \pm 58.8$ & $-0.531-55.522$ & 0.054 \\
\hline - Lower & $104.6 \pm 39.6$ & $103.8 \pm 49.1$ & $-19.239-21.003$ & 0.931 \\
\hline En bloc resection rate, $\mathrm{n}(\%)$ & $62(96.9)$ & $236(99.6)$ & $0.012-1.472$ & 0.053 \\
\hline \multicolumn{5}{|c|}{$\begin{array}{l}\text { Data are analyzed using the } x 2 \text {-test and the Student's } t \text {-test. } \\
\text { Depth of invasion: } M \text {, mucosal cancer; } S M 1 \text {, minimally invasive submucosal cancer, invasion depth }<500 \mu M \text { from the muscularis mucosa; SM2, invasive submucos } \\
\text { cancer, invasion depth } \geq 500 \mu \mathrm{M} \text { from the muscularis mucosa. } \\
{ }^{1} \text { Upper vs Middle }+ \text { Lower } \\
{ }^{2} \text { When the tumor exhibited a mixture of differentiated and undifferentiated types, the histological type was classified according to the major component of the } \\
\text { tumor. } \\
{ }^{3} \mathrm{M} \text { vs SM1+SM2 }\end{array}$} \\
\hline
\end{tabular}

- Table 3 The total dose and the number of bolus injection of the drug.

\begin{tabular}{|l|c|c|}
\hline & Group M (n=58) & Group P (n=216) \\
\hline Total amount of midazolam or propofol, median (range), $\mathrm{mg}$ & $15(5-67.5)$ & $454.5(103-1830)$ \\
\hline Total dose of midazolam or propofol, median (range), $\mathrm{mg} / \mathrm{kg} / \mathrm{h}$ & $0.14(0.05-0.36)$ & $4.39(0.52-14.35)$ \\
\hline The number of bolus injection of midazolam or propofol, median (range), times & $5(1-24)$ & $1(0-9)$ \\
\hline Total amount of pentazocine, median (range), $\mathrm{mg}$ & $30(15-75)$ & $37.5(22.5-75)$ \\
\hline Total dose of pentazocine, median (range), $\mathrm{mg} / \mathrm{kg} / \mathrm{h}$ & $0.25(0.10-0.72)$ & $0.36(0.14-1.00)$ \\
\hline The number of bolus injection of pentazocine, median (range), times & $1(0-6)$ & $3(1-8)$ \\
\hline Data are analyzed using the Mann-Whitney U-test. & & $<0.001$ \\
\hline
\end{tabular}

though no significant difference was found between the two groups for the incidence of hypoxemia ( $>$ Table 5 ).

In terms of awareness after ESD, the percentages of patients in group $P$ who had an OAA/S score of 5 immediately and 1 hour after ESD were significantly higher than those in group $M(P=$ 0.002 and 0.022 , respectively; $>$ Table 6$)$. One patient in group
M experienced nocturnal delirium. This patient, who had no dementia or cerebrovascular disease, showed no vital sign abnormalities during ESD. 
- Table 4 Body movement and cardiorespiratory data during the ESD procedure.

\begin{tabular}{|c|c|c|c|}
\hline & Group M $(n=58)$ & Group P $(n=216)$ & $P$ value \\
\hline Body movement, median (range), times & $3(0-10)$ & $0(0-10)$ & $<0.001$ \\
\hline \multicolumn{4}{|l|}{ Minimum values, median (range) } \\
\hline - Minimum sBP, mmHg & $120.5(76-158)$ & $100.5(57-151)$ & $<0.001$ \\
\hline " Minimum HR, beats/min & $66(41-90)$ & $56(37-83)$ & $<0.001$ \\
\hline - Minimum $\mathrm{SpO}_{2}, \%$ & $97(79-100)$ & $97(79-100)$ & 0.948 \\
\hline " Minimum RR, breats/min & $13(6-19)$ & $10(3-19)$ & 0.005 \\
\hline \multicolumn{4}{|l|}{ Abnormal vital signs, n (\%) } \\
\hline " Hypotension (sBP< 90 mmHg) & $4(6.9)$ & $68(31.5)$ & 0.004 \\
\hline - Bradycardia (HR<50/min) & $4(6.9)$ & $40(18.5)$ & 0.174 \\
\hline - Hypoxemia $\left(\mathrm{SpO}_{2}<90 \%\right)$ & $2(3.4)$ & $15(6.9)$ & 0.683 \\
\hline - Bradypnea, $(\mathrm{RR}<8 / \mathrm{min})$ & $3(5.2)$ & $39(18.1)$ & 0.132 \\
\hline
\end{tabular}

- Table 5 Body movement and cardiorespiratory data during the ESD procedure among the patients with long procedure time ( $>1 \mathrm{hr}$ ).

\begin{tabular}{|c|c|c|c|}
\hline & Group M $(n=52)$ & Group $P(n=189)$ & $P$ value \\
\hline Body movement, median (range), times & $3.5(0-10)$ & $0(0-10)$ & $<0.001$ \\
\hline \multicolumn{4}{|l|}{ Minimum values, median (range) } \\
\hline - Minimum sBP, mmHg & $118.5(76-158)$ & $101(57-151)$ & $<0.001$ \\
\hline - Minimum HR, beats/min & $64(41-82)$ & $56(37-83)$ & $<0.001$ \\
\hline - Minimum $\mathrm{SpO}_{2}, \%$ & $96.5(79-100)$ & $97(79-100)$ & 0.396 \\
\hline - Minimum RR, breats/min & $12(6-19)$ & $10(3-15)$ & 0.024 \\
\hline \multicolumn{4}{|l|}{ Abnormal vital signs, $\mathrm{n}(\%)$} \\
\hline - Hypotension (sBP<90 mmHg) & $4(7.7)$ & $57(30.2)$ & $<0.001$ \\
\hline - Bradycardia (HR<50/min) & $4(7.7)$ & $37(19.6)$ & 0.043 \\
\hline - Hypoxemia $\left(\mathrm{SpO}_{2}<90 \%\right)$ & $2(3.8)$ & $10(5.3)$ & 0.671 \\
\hline - Bradypnea, $(\mathrm{RR}<8 / \mathrm{min})$ & $3(5.8)$ & $38(20.1)$ & 0.015 \\
\hline
\end{tabular}

- Table 6 Awareness after ESD.

\begin{tabular}{|l|l|l|l|l|}
\hline & Group $\mathbf{M}(\mathbf{n}=\mathbf{5 8})$ & Group $\mathbf{P}(\mathbf{n}=\mathbf{2 1 6})$ & $\mathbf{9 5 \%} \mathbf{C l}$ & $\mathbf{P}$ value \\
\hline Immediately after ESD, $\mathrm{n}(\%)$ & $13(22.4)$ & $96(44.4)$ & $0.184-0.708$ & 0.002 \\
\hline One hour after ESD, $\mathrm{n}(\%)$ & $26(44.8)$ & $133(61.6)$ & $0.282-0.311$ & 0.022 \\
\hline Three hours after ESD, $\mathrm{n}(\%)$ & $43(74.1)$ & $179(82.9)$ & $0.298-1.177$ & 0.132 \\
\hline $\begin{array}{l}\text { Data are analyzed using } x^{2} \text {-test. } \\
\text { ESD, endoscopic submucosal dissection }\end{array}$ & & & \\
\hline
\end{tabular}




\section{Discussion}

Non-anesthesiologists are using propofol increasingly for sedation during gastrointestinal endoscopy [19]. Propofol-based sedation can be achieved safely with minimal complication even by non-anesthesiologists, provided that the non-anesthesiologists are trained in its proper use and in response to emergency situations [20]. The efficacy and safety of propofol-based sedation have been demonstrated for endoscopic retrograde cholangiopancreatography and endoscopic ultrasonography [2123]. The present study demonstrated the safety and efficacy of propofol-based sedation in ESD.

The present data also suggest greater effects on cardiorespiratory dynamics in propofol-based sedation. However, propofol-related hypotension, bradycardia, and hypopnea were only observed immediately after sedation induction. No change in cardiorespiratory dynamics requiring treatment was observed during ESD. Reducing the dose of continuous propofol infusion reversed hypotension and bradycardia; hypopnea and hypoxemia were corrected rapidly by increasing the oxygen dose temporarily. Although propofol has some advantages such as rapid onset and shorter duration of action [10], its narrow therapeutic range and appreciable effect on cardiorespiratory dynamics are regarded as disadvantageous [7 -9]. To group M patients, a bolus IV infusion of midazolam or pentazocine was given in the event of body movement, which was generally followed by changes in cardiorespiratory dynamics. However, no patient required ESD to be discontinued as a result of cardiorespiratory dynamic change.

Sedation with continuous propofol infusion has been associated with a significantly lower frequency of body movement during ESD compared to bolus IV infusion of midazolam or propofol [24]. This reported association is consistent with the present study's findings: during ESD, a significantly higher frequency of body movement was observed in group M. For targeting deep sedation, propofol has an effect with continuous infusion; midazolam has an effect with bolus IV infusion because of its half-life. Fundamentally, the two drugs have different uses. We suggest that the continuous infusion is not the reason for effectiveness. Body movements were observed between sedation induction and the start of the ESD procedure in both groups. In group $\mathrm{M}$, body movements requiring trunk restraint were also observed during ESD in many cases. One patient in group $\mathrm{M}$ had severe body movement that required discontinuation of the procedure. This patient had diabetes, hypertension, dyslipidemia, and mild liver dysfunction, but had no history of heavy alcohol use or regular use of benzodiazepines.

Patients in group $\mathrm{P}$ had better postoperative awareness immediately and at 1 hour after ESD. Propofol has a short duration of action [10] and therefore engenders good postoperative awareness, which might lead to lower incidence of secondary complications such as unrest and subsequent falls and/or a fall from a bed.

This study has several limitations. First, this study was not a randomized controlled trial for which patients were retrospectively assigned to study groups at different time points. Sec- ond, the study was conducted at a single center with a small sample size.

\section{Conclusion}

During ESD for gastric cancer, propofol-based sedation provided stable sedation with a lower frequency of body movement and better postoperative awareness than those of midazolambased sedation. Continued monitoring of the respiratory rate allowed us to understand the patient's respiratory condition immediately. The need remains to verify these findings further in a multicenter, randomized controlled trial.

\section{Acknowledgements}

We express our gratitude to all endoscopy medical staff for their collaboration and assistance with the endoscopic procedures.

\section{Competing interests}

None

References

[1] Gotoda T, Iwasaki M, Kusano C et al. Endoscopic resection of early gastric cancer treated by guideline and expanded National Cancer Centre criteria. Br J Surg 2010; 97: 868-871

[2] Oda I, Gotoda T, Hamanaka H et al. Endoscopic submucosal dissection for early gastric cancer: technical feasibility, operation time and complications from a large consecutive series. Dig Endosc 2005; 17 : $54-58$

[3] Gotoda T. Endoscopic resection of early gastric cancer. Gastric Cancer 2007; 10: $1-11$

[4] Nonaka S, Oda I, Nakaya T et al. Clinical impact of a strategy involving endoscopic submucosal dissection for early gastric cancer: determining the optimal pathway. Gastric Cancer 2011; 14: 56-62

[5] Imagawa A, Okada H, Kawahara Y et al. Endoscopic submucosal dissection for early gastric cancer: results and degrees of technical difficulty as well as success. Endoscopy 2006; 38: 987-990

[6] Kiriyama S, Gotoda T, Sano $\mathrm{H}$ et al. Safe and effective sedation in endoscopic submucosal dissection for early gastric cancer: a randomized comparison between propofol continuous infusion and intermittent midazolam injection. J Gastroenterol 2010; 45: 831-837

[7] Skues MA, Prys-Roberts C. The pharmacology of propofol. J Clin Anesth 1989; 1: $387-400$

[8] Yamagata T, Hirasawa D, Fujita N et al. Efficacy of Propofol sedation for endoscopic submucosal dissection (ESD): assessment with prospective data collection. Intern Med 2011; 50: 1455-1460

[9] Larijani GE, Gratz I, Afshar M et al. Clinical pharmacology of propofol: an intravenous anesthetic agent. DICP 1989; 23: $743-749$

[10] Kanto J, Gepts E. Pharmacokinetic implications for the clinical use of propofol. Clin Pharmacokinet 1989; 17: 308-326

[11] Riphaus A, Gstettenbauer T, Frenz MB et al. Quality of psychomotor recovery after propofol sedation for routine endoscopy: a randomized and controlled study. Endoscopy 2006; 38: 677-683 
[12] Sipe BW, Rex DK, Latinovich D et al. Propofol versus midazolam/meperidine for outpatient colonoscopy: administration by nurses supervised by endoscopists. Gastrointest Endosc 2002; 55: 815-825

[13] Weston BR, Chadalawada V, Chalasani $N$ et al. Nurse-administered propofol versus midazolam and meperidine for upper endoscopy in cirrhotic patients. Am J Gastroenterol 2003; 98: 2440-2447

[14] Carlsson U, Grattidge P. Sedation for upper gastrointestinal endoscopy: a comparative study of propofol and midazolam. Endoscopy 1995; 27: $240-243$

[15] Koshy G, Nair S, Norkus EP et al. Propofol versus midazolam and meperidine for conscious sedation in Gl endoscopy. Am J Gastroenterol 2000; 95: 1476 - 1479

[16] Vargo JJ, Zuccaro GJr, Dumot JA et al. Gastroenterologist-administered propofol versus meperidine and midazolam for advanced upper endoscopy: a prospective, randomized trial. Gastroenterology 2002; 123: $8-16$

[17] Kiriyama S, Naitoh H, Kuwano H. Propofol sedation during endoscopic treatment for early gastric cancer compared to midazolam. World J Gastroenterol 2014; 20: 11985-11990

[18] American Society of Anesthesiologists. Task Force on Sedation and Analgesia by Non-Anesthesiologists. Practice guidelines for sedation and analgesia by non-anesthesiologists AnesthesiologyAmerican Society of Anesthesiologists; 2002; 96: 1004-1017

[19] Cohen LB, Wecsler JS, Gaetano JN et al. Endoscopic sedation in the United States: results from a nationwide survey. Am J Gastroenterol 2006; 101: $967-974$

[20] Friedrich K, Stremmel W, Sieg A. Endoscopist-administered propofol sedation is safe - a prospective evaluation of 10,000 patients in an outpatient practice. J Gastrointestin Liver Dis 2012; 21: 259-263

[21] Jung M, Hofmann C, Kiesslich R et al. Improved sedation in diagnostic and therapeutic ERCP: propofol is an alternative to midazolam. Endoscopy 2000; 32: $233-238$

[22] Wehrmann T, Kokabpick S, Lembcke B et al. Efficacy and safety of intravenous propofol sedation during routine ERCP: a prospective, controlled study. Gastrointest Endosc 1999; 49: 677-683

[23] Yusoff IF, Raymond G, Sahai AV. Endoscopist administered propofol for upper-GI EUS is safe and effective: a prospective study in 500 patients. Gastrointest Endosc 2004; 60: 356-360

[24] Park CH, Shin S, Lee SK et al. Assessing the stability and safety of procedure during endoscopic submucosal dissection according to sedation methods: a randomized trial. PLoS One 2015; 10: e0120529 